FACTA UNIVERSITATIS

Series: Mechanical Engineering Vol. 14, N 2 2, 2016, pp. 147 - 158

Original scientific paper

\title{
CAD/CAM DESIGN AND THE GENETIC OPTIMIZATION OF FEEDERS FOR SAND CASTING PROCESS
}

\author{
UDC 621.7
}

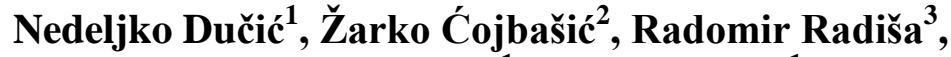 \\ Radomir Slavković ${ }^{1}$, Ivan Milićević ${ }^{1}$ \\ ${ }^{1}$ Faculty of Technical Sciences, Čačak, University of Kragujevac \\ ${ }^{2}$ Faculty of Mechanical Engineering, University of Niš \\ ${ }^{3}$ Research and Development Institute Lola L.T.D.
}

\begin{abstract}
The paper proposes methodology of feeder design and optimization for sand casting process. Casting part is a part of excavator buckets, i.e. holder of the cutting tooth. Process of design and optimization is based on the application of the rules, which are the result of many years of work researchers in the field of metal casting. Computer Aided Design (CAD) is used as a methodology in the design of feeders. Genetic Algorithm (GA) as an artificial intelligence technique is used in the optimization process of the feeder geometry. Computer Aided Manufacturing (CAM) is used as methodology that involves numerical simulation of the casting process. Numerical simulation is used to verify the validity of the optimized geometry of the feeding system.
\end{abstract}

Key Words: Sand Casting, Feeder System, Optimization, Genetic Algorithm, Numerical Simulation

\section{INTRODUCTION}

Cooling of casting part causes shrinkage of material, therefore, the basic function of feeders is to compensate for the deficiency of metal during casting part solidification. Unlike filling as a relatively short process, feeding is a necessary, time-consuming and slow one. Casting part cooling involves three phases of volume contraction (shrinkage) - liquid shrinkage, solidification shrinkage and solid shrinkage [1]. Volume contraction is manifested through some adverse phenomena, i.e. internal shrinkage voids, surface deformation or dishing, and

Received August 15, 2015 / Accepted January 28, 2016

Corresponding author: Nedeljko Dučić

Faculty of Technical Sciences Čačak, University of Kragujevac, Svetog Save 65, 32000 Čačak

E-mail: nedeljko.ducic@ftn.kg.ac.rs 
surface puncture. The elimination of the above side effects is obtained by designing feeders which are removed after cooling the casting part.

Optimal design of feeders, in addition to providing higher quality products, also provides consumption savings of molten metal in the casting process. The total volume of feeder should be minimized to improve the casting yield and productivity [2]. Jacob et al. (2004) presented the integration of Genetic Algorithm (GA) and CAD in the design and optimization of feeders in casting process. The synergy of CAD and genetic algorithms generates a class of optimal feeders that also satisfy the standard criteria set up in literature [3]. Tavakoli and Davami (2007) focus on the design of the feeding system in the sand casting process using Topology optimization (Solid Isotropic Material with Penalisation method) [4]. Tavakoli and Davami (2009) combine finite-difference analysis of the solidification process with evolutionary topology optimization to systematically improve the feeding system design [5]. Kotas et al. (2010) summarize the findings of multi-objective optimization of a gravity sand-cast steel part for which an increase of the casting yield via feeder optimization is considered. This is accomplished by coupling a casting simulation software package with an optimization modulus [6]. Sutaria et al. (2011) present a new approach to evaluating and optimizing casting feeding system design using feed-paths. The feed-paths are computed by Vector Element Method (VEM) [7]. Choudhari et al. (2013) describe the parameters to be considered while designing a feeder of an optimum size to get higher casting Yield. Theoretical design model has been analyzed in ANSYS 12.0 simulation software to ensure that shrinkage porosity is completely eliminated from casting [8]. Campbell (1991, $2004 \&$ 2011) propose seven conditions for feeding casting part: 1. Do not feed (unless necessary); 2. The heat-transfer requirement; 3. Mass-transfer (volume) requirement; 4. The junction requirement; 5. Feed path requirement; 6. Pressure gradient requirement and 7. Pressure requirement [9]. Those conditions were the starting points for the design and optimization of feeders in the research studies.

This paper presents a methodology of designing and optimizing the feeders for casting a cutting tooth holder. Based on the rules given in [9], using the Computer Aided Design/ Computer Aided Manufacturing systems and Genetic Algorithm (as a technique of the artificial intelligence), the optimal feeding system for casting part is obtained. The paper includes three crucial rules proposed by Campbell: (2) The heat-transfer requirement, (3) Mass-transfer (volume) and (5) Feed path requirement. Those rules are included in the optimization process through the initial setup of the feeding system, definition of fitness function and definition constraints. Numerical simulation confirm the validity of the implemented methodology for feeder design and optimization.

\section{FEEDER SYSTEM DESIGN}

Casting part is a part of excavator buckets, i.e. a cutting tooth holder (its CAD model is shown in Fig. 1). Production technology of the cutting tooth holder is sand casting. Molds for single use are made of a mixture of sand, binders and additives. A quartz sand ( $\mathrm{SiO} 2)$ is usually used in making molds. The core is more exposed to the molten metal and high temperatures. Therefore, the core is made of sand with rough grains. 


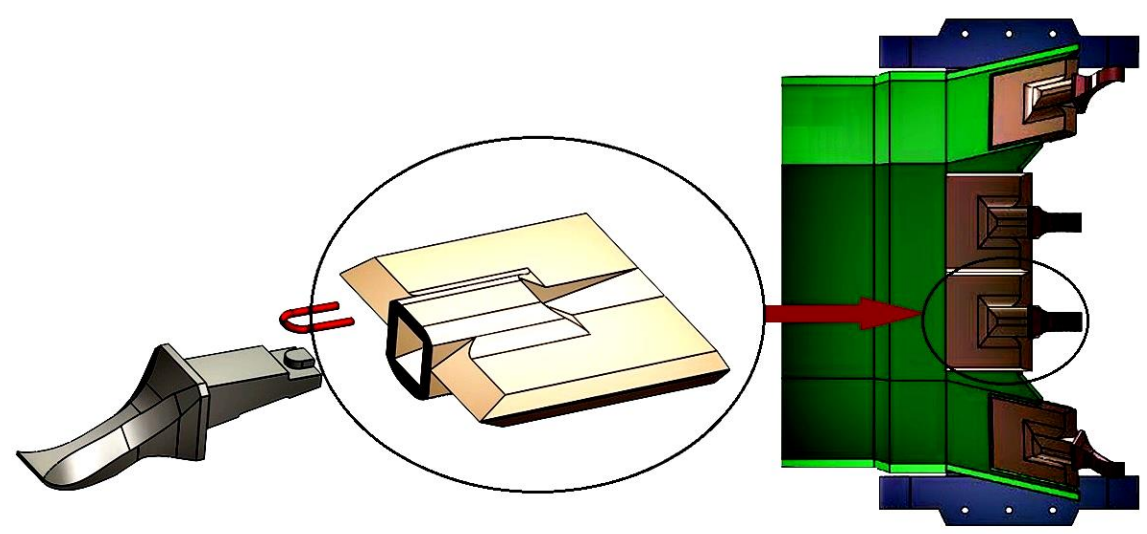

Fig. 1 CAD models: cutting tooth, cutting tooth holder and an entire excavator bucket

Fig. 2 presents the casting part (a cutting tooth holder) and gating system with its marked elements.

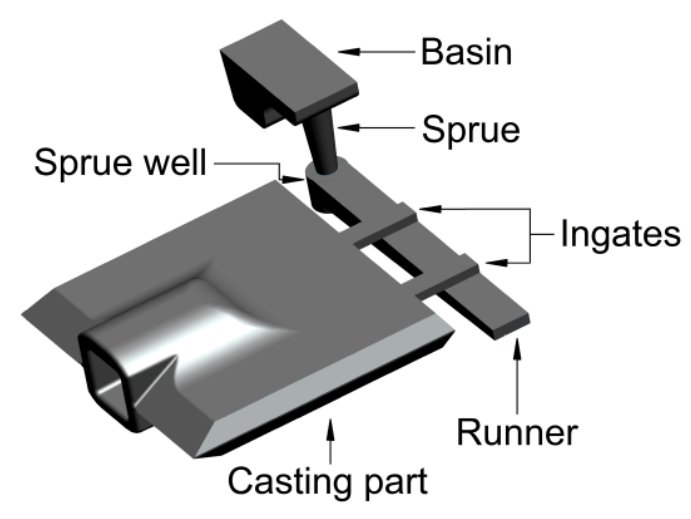

Fig. 2 Gating system for casting a cutting tooth holder

The first step in the feeding system design is to define the type of feeder, the number of feeders and their position in the system of casting. The selected type of feeders is a cylindrical open feeder because of the largest modulus (the cylinder has the smallest surface area per volume). Place of feeders is determined so as to provide "directional solidification", thus achieving the solidification of thinner to thicker cross sections of the casting part and finally in the feeders. The number of feeders depends on the feeding distance. There has been much experimental effort to determine feeding distances. The early work by Pellini and his co-workers (summarized by Beeley (1972)) at the US Naval Materials Laboratory is a classic investigation that has influenced the thinking on the concept of feeding distance ever since. The number of feeders and feeding distance are defined on the basis of the rules: "Feed path requirement - Feeding distance". Therefore: 


$$
L_{d}=4.5 T
$$

where: $L_{d}$ - feeding distance, $T$ - thickness of the casting. Approximate dimensions of casting part are $295 \times 320 \times 40 \mathrm{~mm}$, so the recommended feeding distance $L_{d}=180 \mathrm{~mm}$. Given the dimensions of the base of casting part $(295 \times 320 \mathrm{~mm})$, it is necessary to use two feeders positioned to meet the requirement of distance feeding $L_{d}$. Namely, the proposed solution comprises two cylindrical symmetric feeders intended to compensate for volume shrinkage of metal (Fig. 3).

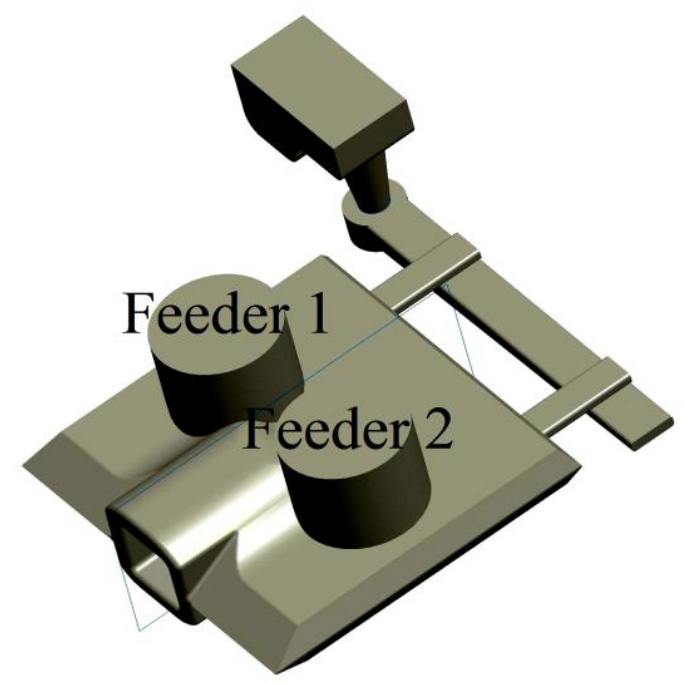

Fig. 3 The proposed gating system with feeders

The next challenge in the design of the feeding system is the geometry feeders' optimization.

\section{GA OPTIMIZATION OF FEEDER}

Optimization of feeders is based on the use of Genetic Algorithm (GA) and rules: (2) The heat-transfer requirement and (3) Mass-transfer (volume) requirement. Genetic algorithms (GAs) are a family of adaptive search algorithms described and analyzed in references [10-14]. GAs derive their name from the fact that they are loosely based on models of genetic change in a population of individuals. These models consist of three basic elements: (1) a Darwinian notion of 'fitness', which governs the extent to which an individual can influence future generations; (2) a 'mating operator', which produces offspring for the next generation; and (3) 'genetic operators', which determine the genetic makeup of offspring from the genetic material of the parents [13]. The main objective of the optimization is to find the value of diameter (D) and height $(\mathrm{H})$ of the feeder, with minimizing volume of the feeder and respecting constraint specified on the rules. 


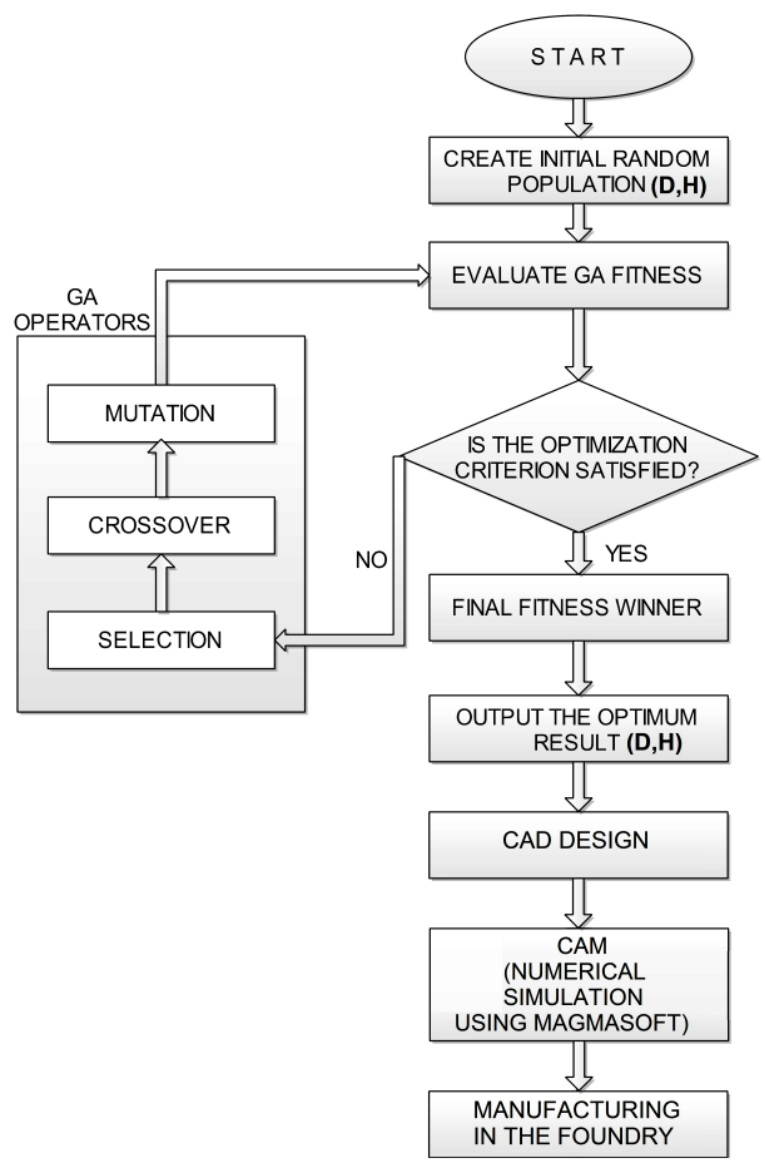

Fig. 4 Algorithm of optimization and design of feeders

\subsection{Fitness function}

Defining the fitness function is one of the major steps of optimization via GA. Creating the fitness function is based on the rule: The heat-transfer requirement. The heat-transfer requirement for successful feeding can be stated as follows: the freezing time of the feeder must be at least as long as the freezing time of the casting [9]. Casting solidification time can be predicted using Chvorinov's Rule shown by the equation:

$$
t_{s}=C\left(\frac{V}{A}\right)^{2}
$$

where $t_{s}$ is the total solidification time of the part or feeder, $C$ is a mold constant, $V$ is the volume of metal, and $A$ is the total surface area of the part or feeder. As the feeder serves to compensate for the volume shrinkage in the casting part, it needs to be the final link of the solidification chain, i.e. it should be the last to solidify in directional solidification process. The longest solidification time for a given volume is the one where the shape of 
the part has the minimum surface area. The cylinder has the smallest surface area per volume and can easily be made, which was crucial when designing the feeder. Feeder modulus is taken to be a minimum of $20 \%$ higher than the modulus of casting part, i.e. modulus of part who feeds:

$$
M_{\text {feeder }}>1.2 \cdot M_{\text {casting }} \text { part }
$$

The modulus for a cylindrical feeder is given by the following equation:

$$
M_{\text {feeder }}=\frac{D H}{2 D+4 H}
$$

Based on the values of volume and surface of the casting part, obtained by analyzing CAD model $\left(V_{c}=3661113.8 \mathrm{~mm}^{3}\right.$ and $\left.A_{c}=253716.66 \mathrm{~mm}^{2}\right)$, the casting part modulus is: $M_{\text {casting_part }}=14.43$. As the feeders are symmetrical and designed that each of them should feed half of the casting part, relation (5) gives the final expression of fitness function that minimizes:

$$
F=M_{\text {feeder }}-1.2 \frac{M_{\text {casting_part }}}{2}=\frac{D H}{2 D+4 H}-8.66>0
$$

\subsection{Defining constraints}

Constraint is based on the rule Mass-transfer (volume) requirement. The fulfillment of the conditions given in the rule "The heat-transfer requirement", does not guarantee the fulfillment of the conditions given in the rule "Mass-transfer (volume) requirement". Although the feeder may have been provided of such a size that it theoretically would contain liquid until after the casting is solid, in fact it may still be too small to deliver the volume of feed liquid that the casting demands. Thus it will be prematurely sucked dry, and the resulting shrinkage porosity will extend into the casting. This is because they are themselves freezing at the same time as the casting, depleting the liquid reserves of the reservoir. Effectively, the feeder has to feed both itself and the casting. We can allow for this in the following way. If we denote efficiency $\varepsilon$ of the feeder as the ratio (volume of available feed metal) / (volume of feeder, $V_{f}$ ) then the volume of feed metal is, of course $\varepsilon \cdot V_{f}$. If the solidification shrinkage of the liquid is $\alpha$, during freezing, then the feed demand from both the feeder and casting together is $\alpha\left(V_{f}, V_{c}\right)$, and hence [15]:

$$
\varepsilon V_{f}=\alpha\left(V_{f}+V_{c}\right)
$$

Solving for the feeder volume yields:

$$
V_{f} \geq \frac{\alpha V_{c}}{\varepsilon-\alpha} \geq 0.4 \frac{V_{c}}{2} \Rightarrow \frac{D^{2} H}{4} \pi \geq 0.2 V_{c}
$$

where: $\alpha$ - solidification shrinkage of the liquid during freezing ( $\alpha=4$, for steels the fcc structure applies above $0.1 \%$ carbon where the melt solidifies to austenite), $\varepsilon=14 \%$ for a normal cylindrical feeder, $V_{c} / 2$ - because one feeder feeds half of the casting part. The relation (7) is a constraint in the optimization process of geometry feeders. 


\subsection{Optimization results}

Search domains of size values that are being optimized are given in Table 1. The upper and lower limits are set in accordance with the proposed geometry of the casting part and mold. Feeder height is limited by the mold height.

Table 1 Optimal values search domain

\begin{tabular}{lcc}
\hline & $\mathrm{D}(\mathrm{mm})$ & $\mathrm{H}(\mathrm{mm})$ \\
\hline Lower bound & 10 & 10 \\
Upper bound & 150 & 80 \\
\hline
\end{tabular}

The population range is 100 individuals, with 100 generations at maximum. Stochastic universal sampling algorithm is used in the selection. The population is seen as mapped on the roulette-wheel, larger parts of the wheel belonging to strings with lower fitness (since it is a minimization problem). $\mathrm{N}$ pointers are evenly placed on the roulette, $\mathrm{N}$ being the number of individuals in a population. A population is generated by rotating the roulette once. Uniform crossover is used as the operator of the crossing. The coefficient of the 'crossover fraction' is 0.8 . Crossover fraction defines a portion of the new population derived from a crossing (non-elite individuals), its value being between 0 and 1 . No more than two elite individuals are to be transferred to the next generation. The operation of GA is terminated as early as the 92 generation due to the violation of specified limits. The obtained optimized values are as follows: $D=105 \mathrm{~mm}$ and $H=80 \mathrm{~mm}$. Fig. 5 shows the position of the proposed feeders.
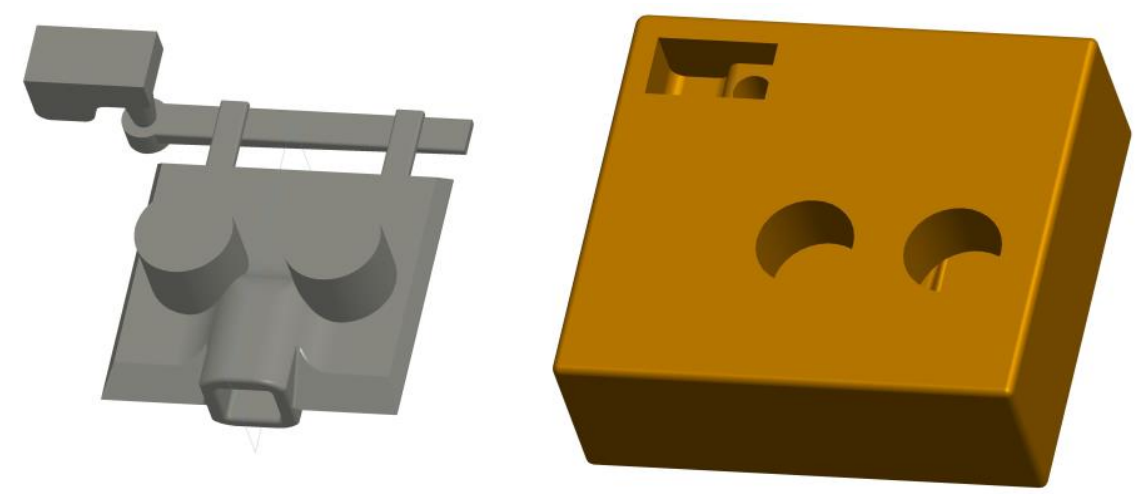

Fig. 5 The proposed gating system with feeders and sand mold

\section{NUMERICAL SIMULATION}

In addition to practical knowledge applied in foundries, simulation programs are used to better understand the casting process and manage it more easily. The primary objective of simulation is to confirm the validity of the methodology applied in the optimization and design of the feeding system, and reduce the cost and ensure reliable and quality production 
accordingly. The entire casting process, from filling the mold cavity with liquid metal and all the way to solidification and feeding is available as a good representation of the physical model. Computer 'Cold Casting' allows improving the process step by step [16]. Geometry casting is substantially facilitated, i.e. it is easy to perform changes in the geometry of the casting part, the position of feeder and core, etc. as well as in the parameters of the casting process (temperature of the casting part, filling speed, etc.). Modern software package MagmaSoft 5 (Version 5.2) is used to simulate the casting process [17]. Model of casting part, as well as models of the optimized gating system and feeders' geometry, are used in the STL graphical format.

In our paper, the alloy which is being the subject of the casting simulation is not available in the software database, therefore it is required that the data be loaded into the database. A material with chemical composition and properties similar to the one to be cast are chosen from the database. The chosen material has its name changed and loaded into the user's part of the database whereupon it is possible to load a new composition of chemical elements and features for the material to be cast. The properties of the new material remain in the database. Chemical composition of an alloy affects its castability and behavior during the casting process, as well as the properties of the final casting part. The paper describes simulation of casting steel of chemical composition $0.5 \% \mathrm{C}, 1.4 \%$ Mn, $0.035 \% \mathrm{P}, 0.035 \% \mathrm{~S}, 0.4 \% \mathrm{Si}, 0.1 \% \mathrm{~V}$. Compared to standard content of chemical elements in steel (designation GS30Mn5), contents of carbon, manganese and vanadium are changed. Initial temperatures of steel, sand mold and coldbox are $1600{ }^{\circ} \mathrm{C}, 40{ }^{\circ} \mathrm{C}$ and $20^{\circ} \mathrm{C}$ respectively. Basic limiting conditions at casting are as follows: Liquidus temperature $1498^{\circ} \mathrm{C}$; Solidus temperature of $1406{ }^{\circ} \mathrm{C}$; Criterion temperature 1: $1415.2{ }^{\circ} \mathrm{C}$. At a temperature named "criterion temperature 1 " feeding of the cast part is calculated as the default value; Criterion temperature 2: $1500{ }^{\circ} \mathrm{C}$. Criterion temperature 2 is calculated temperature based on the cooling rate and gradient of change in temperature over time; Latent heat $254 \mathrm{~kJ} / \mathrm{kg}$; Feeding effectivity $30 \%$. Feeding effectivity criterion shows the volume of material to which macroscopic feeding is possible; Surface tension coefficient $1.496 \mathrm{~N} / \mathrm{m}$. Subsequent to defining groups and types of materials in the casting system, it is necessary to determine heat transfer coefficients - HTC for pairs of materials in contact. In sand casting the mold and the core surfaces are coated so as to affect thermal behavior of the mold and core.

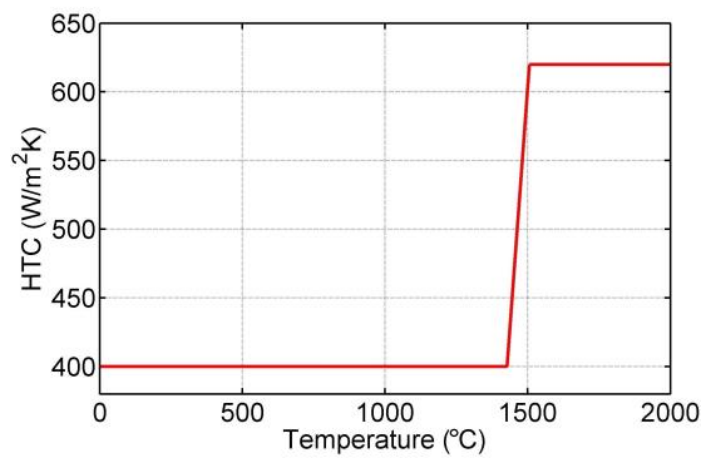

Fig. 6 Heat transfer coefficient in Low Alloy (LA)-steel-coat pair 
The database provides data on HTC coefficients for different material pairs. Fig. 6 shows the HTC for low-alloy steel and the mold coated with a layer of a particular thickness. Mold cavity and core are coated with a layer of $0.1 \mathrm{~mm}$ thick. Heat transfer coefficients - HTC applied in the simulation are used from the database software (in Sand-Core we use constant $\mathrm{HTC}=800 \mathrm{~W} / \mathrm{m}^{2} \mathrm{~K}$, in Feeder-Sand and Gate-Sand we use the temperature-dependent Steel-Sand coefficient). Each HTC can be modified according to the specific conditions in the drive, which includes the additional thermal conductivity. Properly defined geometry network is in the basis of any simulation and is essential for the accuracy of the simulation results. The fineness and density of the network enables more accurate results but the simulation requires longer time. The total number of final volumes is one million, whereby the number of volume elements pertaining to metal 157611, without critical elements present. To bring the simulation into correlation with the physical process in reality requires that at least 3 elements of network volume are provided between two adjacent walls. In our study, the number of volumes between two adjacent walls on the axes $x / y / z$ is $154 / 130 / 49$, respectively. To define solidification, i.e. cooling of the casting part, parameters and limiting conditions are required. Primarily, time or temperature at which the solidification simulation ends need to be specified first. In our study, the final temperature in the simulation is $200^{\circ} \mathrm{C}$.

The FEEDMOD criterion (Fig. 7) is specifically designed for sand casting. The objective is to change the value of 'Feedmod' to allow directional solidification to feeders. The highest values should be in the feeder; they gradually become lower in the casting part. The values of the thermal module confirm the validity of the proposed optimized feeders.

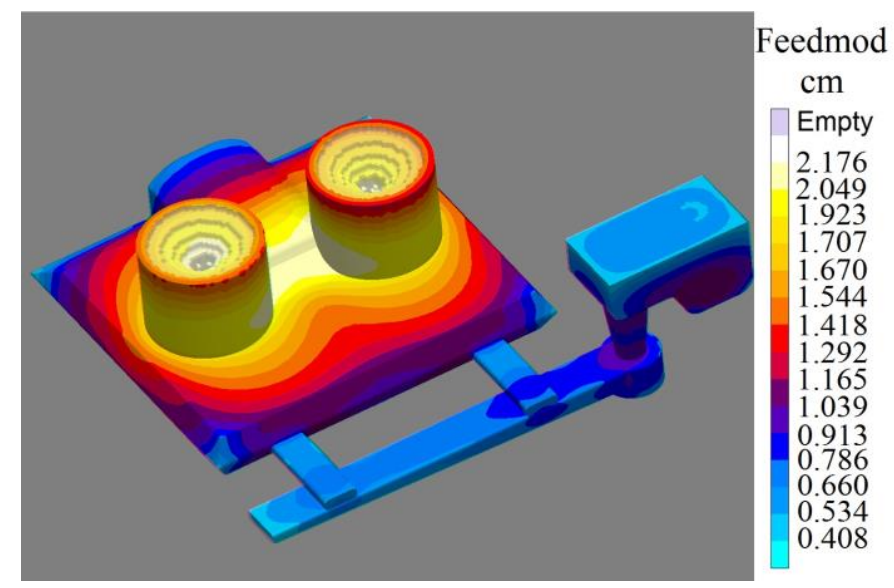

Fig. 7 Feedmod criterion

LIQUIDUS TO SOLIDUS criterion shows the time needed for a material to pass from liquid to solid state. It helps us to discover areas in the casting part that solidify later, particularly the volumes which solidified after the feeding time (isolated volume). Fig. 8 confirms the correctness of the designed gating system and feeders by this criterion, given that the solidification period is the longest in the feeding area. HOT SPOT result shows the volumes of metals that solidify last. It helps us to identify the areas containing residual 
liquid metal. It also enables us to foresee possible macroscopic feeding of the volume from the feeder. Based on Fig. 9, there is a volume that solidifies in the feeder, which is a prerequisite for a regular cast.

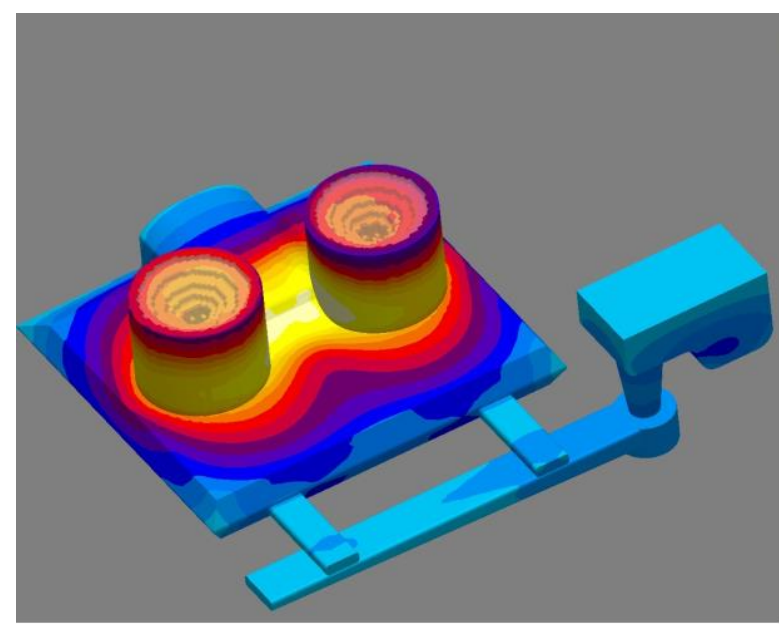

Liquidus to Solidus

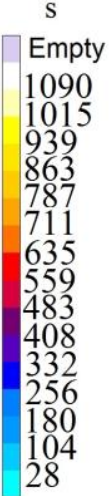

Fig. 8 Time elapsed from liquidus to solidus temperature

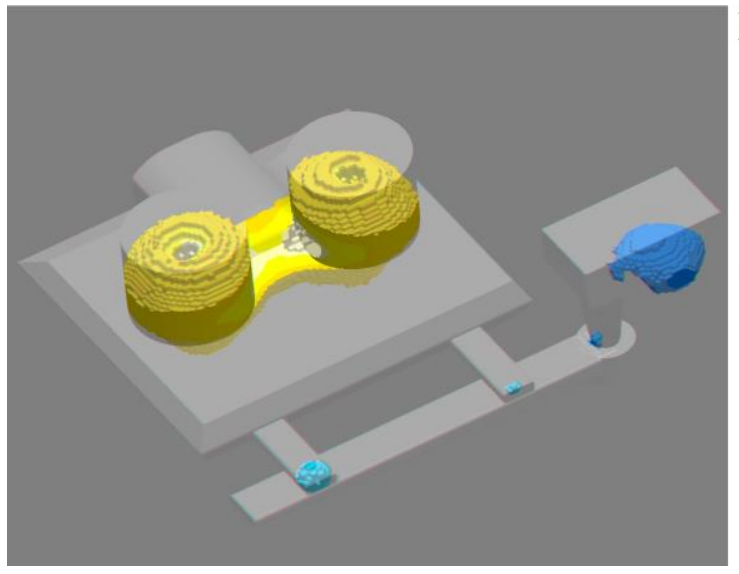

Hot Spot

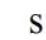

Empty

1100

1041

971

831

762

692

622

553

483

413

274

134

Fig. 9 HOT SPOT criterion

TOTAL POROSITY result shows cumulative porosity and microporosity in a single result, i.e. maximum values of porosity and micro-porosity. Fig. 10 shows the X-ray total porosity in the casting part and that through the mid-section of the feeder. Total porosity is expressed through percentage (\%). The $\mathrm{x}$-ray view of the casting part renders conclusion that alloy casting technology provides required quality. 


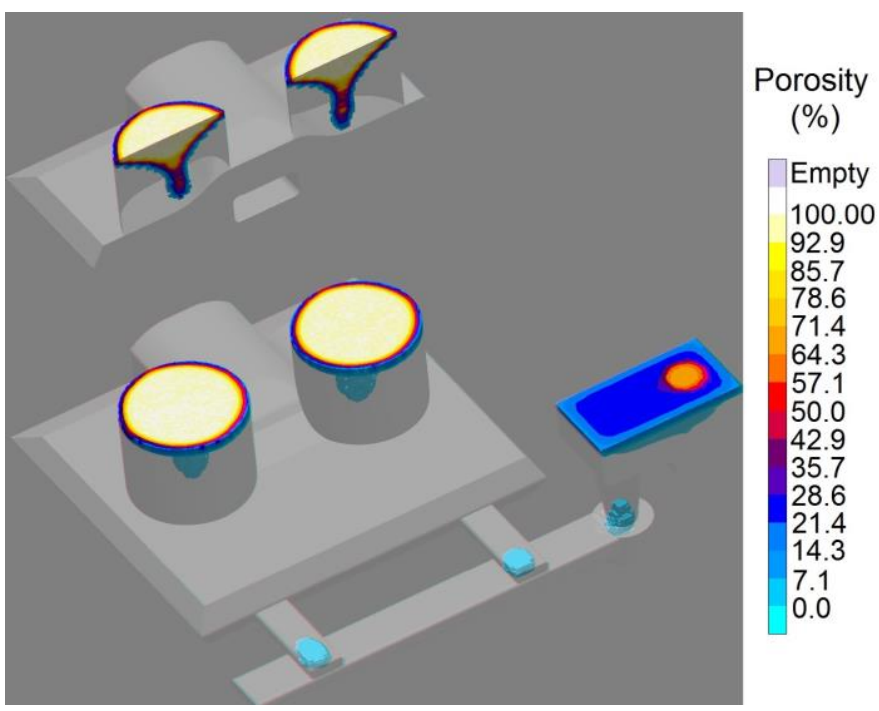

Fig. 10 POROSITY criterion

\section{CONCLUSION}

The aim of this study is to present a methodology for optimizing the geometry of the feeding system for sand casting process based on the application of genetic algorithm. The result of the optimization are diameter and height of feeders $(D=105 \mathrm{~mm}$ and $H=80$ $\mathrm{mm}$ ), obtained as function of minimizing volume of feeder. Based on the obtained results of the optimization, the entire feeding system is designed by means of CAD software. Performed numerical simulations confirm the correctness of the designed optimized feeding system in view of all the criteria. The proposed methodology of design and optimization provides a complete filling of the mold cavity, directional solidification and eliminate porosity.

Acknowledgements: The paper is a part of the research done within the project TR35037 and TR35015.

\section{REFERENCES}

1. ASM Handbook Committee, 2002, ASM Metals HandBook, ASM International, 1246 p.

2. Ravi, B., Srinivasan, M., 1996, Casting solidification analysis by modulus vector method, Int. J. Cast. Met. Res., 9(1), pp. 1-7.

3. Jacob, E., Sasikumar, R., Praveen, B., Gopalakrishna, V., 2004, Intelligent design of feeders for castings by augmenting CAD with genetic algorithms, Journal of Intelligent Manufacturing, 15(3), pp. 299-305.

4. Tavakoli, R., Davami, P., 2008, Optimal riser design in sand casting process by topology optimization with SIMP method I: Poisson approximation of nonlinear heat transfer equation, Structural and Multidisciplinary Optimization, 36(2), pp. 193-202.

5. Tavakoli, R., Davami, P., 2009, Optimal riser design in sand casting process with evolutionary topology optimization, Structural and Multidisciplinary Optimization, 38(2), pp. 205-214. 
6. Kotas, P., Tutum, C. C., Hattel, J. H., Snajdrova, O., Thorborg, J., 2010, A casting Yield optimization case study: forging ram, International Journal of Metalcasting, 4(4), pp. 61-76.

7. Sutaria, M., Joshi, D., Jagdishwar, M., Ravi, B., 2011, Automatic optimization of casting feeders using feedpaths generated by VEM, Proceedings of the ASME 2011 International Mechanical Engineering Congress \& Exposition, 2011, Denver, Colorado, USA.

8. Choudhari, C. M., Dalal, N. S., Ghude, A. P., Sankhe, P. P., Dhotre A.S., 2013, Design and analyisis of riser for sand casting, International Journal of Students Research in Technology \& Management, 1(2), pp. 176-191.

9. Campbell, J., 2011, Complete casting Handbook, 1st Edition, Elsevier, 661 p.

10. Holland, J. H., 1992, Adaptation in natural and artificial systems, MI: University of Michigan Press, Ann Arbor, $82 \mathrm{p}$.

11. De Jong, K., 1980, Adaptive system design: A genetic approach, IEEE Transactions on Systems, Man, and Cybernetics, 10(9), pp. 556-574.

12. De Jong, K., 1985, Genetic algorithms: A 10 year perspective, Proceedings of the First International Conference on Genetic Algorithms and Their Applications, Pittsburgh, PA: Lawrence Erlbaum.

13. De Jong, K., 1988, Learning with Genetic Algorithms: An Overview, Machine Learning, 3(2-3), pp. 121-138.

14. Goldberg, E. D., 2006, Genetic Algorithms, Pearson Education, 62 p.

15. Kotas, P., 2011, Integrated modeling of process, structures and performance in cast parts, Ph.D. Thesis, Technical University of Denmark - Department of Mechanical Engineering, Denmark, $50 \mathrm{p}$

16. Fang, Y., Hu, J., Zhou, J., Yu, Y., 2014, Numerical Simulation of Filling and Solidification in Exhaust Manifold Investment Casting, International Journal of Metalcasting, 8(4), pp. 39-45.

17. Jeong, S., Jin, C., K., Seo, H., Y., Kim, J., D., Kang, C., G., 2015, Mold structure design and casting simulation of the high-pressure die casting for aluminum automotive clutch housing manufacturing, The International Journal of Advanced Manufacturing Technology, doi 10.1007/s00170-015-7566-4. 